\title{
Clinical Reasoning Skills in AAC Intervention Planning: Investigating the Expert-Novice Gap
}

\author{
Allison M. Sauerwein \\ Southern Illinois University Edwardsville, ameder@siue.edu \\ Jane R. Wegner \\ University of Kansas, jwegner@ku.edu \\ DOI: https://doi.org/10.30707/TLCSD4.2/XND08764
}

Follow this and additional works at: https://ir.library.illinoisstate.edu/tlcsd

Part of the Speech Pathology and Audiology Commons

\section{Recommended Citation}

Sauerwein, Allison M. and Wegner, Jane R. (2020) "Clinical Reasoning Skills in AAC Intervention Planning: Investigating the Expert-Novice Gap," Teaching and Learning in Communication Sciences \& Disorders: Vol. 4: Iss. 2, Article 7.

DOI: https://doi.org/10.30707/TLCSD4.2/XND08764

Available at: https://ir.library.illinoisstate.edu/tlcsd/vol4/iss2/7

This Scholarship of Teaching and Learning Research is brought to you for free and open access by ISU ReD: Research and eData. It has been accepted for inclusion in Teaching and Learning in Communication Sciences \& Disorders by an authorized editor of ISU ReD: Research and eData. For more information, please contact ISUReD@ilstu.edu. 


\title{
Clinical Reasoning Skills in AAC Intervention Planning: Investigating the Expert- Novice Gap
}

\begin{abstract}
Clinical reasoning skills underlie the decisions speech-language pathologists (SLPs) make during practice. Although clinical reasoning is included in speech-language pathology accreditation standards in the United States, there is limited research on preservice SLPs' development or use of clinical reasoning skills. Because clinical reasoning skills specific to augmentative and alternative communication (AAC) service provision have not been identified or reported in depth, this qualitative study focused on two cases of children with developmental disabilities who used AAC systems. Eight novice (i.e. preservice) SLPs and eight expert SLPs completed think-aloud tasks while they developed intervention plans, which made their clinical reasoning skills observable. Responses were transcribed for qualitative analysis. Six clinical reasoning skills were identified: summarizing, interpreting, hypothesizing, rationalizing, comparing and deferring. Expert and novices used four of these clinical reasoning skills similarly; however, there were differences among the remaining two skills. Novices deferred more frequently during the tasks and were limited in their ability to make comparisons to the fictional cases as compared to the experts. The expert-novice gap in clinical reasoning presents implications for teaching preservice SLPs in the classroom and the clinic.
\end{abstract}

\section{Keywords}

clinical reasoning, clinical decision-making, think-aloud, augmentative and alternative communication, intervention planning

\section{Cover Page Footnote}

Allison M. Sauerwein, Department of Speech-Language-Hearing: Sciences and Disorders, University of Kansas. Jane R. Wegner, Department of Speech-Language-Hearing: Sciences and Disorders, University of Kansas. Allison M. Sauerwein is now at Department of Applied Health, Southern Illinois University Edwardsville. This manuscript is based on the first author's doctoral dissertation. Correspondence concerning this article should be addressed to Allison Sauerwein, Department of Applied Health, Campus Box 1147, Southern Illinois University Edwardsville, Edwardsville, IL 62026. Email: ameder@siue.edu The authors would like to acknowledge the students and speech-language pathologists who participated in the study; Karleen Walters, Sarah Ginsberg, and Jennifer Friberg for their contributions to this study; and Nancy Brady, Matt Gillispie, Holly Storkel, and Meagan Patterson their service on the first author's dissertation committee. 
Speech-language pathologists (SLPs) use clinical reasoning skills to make countless decisions during intervention. When planning for intervention, SLPs make decisions about activities, materials, facilitation strategies, and data collection. SLPs often further adjust those plans in the moment during treatment. McAllister and Rose (2008) define clinical reasoning processes as mental tasks, or "the often intangible, rarely explicated thought processes that lead to the clinical decisions that [SLPs] make" (p. 398). Rather than a linear process, clinical reasoning is a series of interwoven cognitive processes that lead to a clinical decision (McAllister \& Rose, 2008). SLPs use multiple skills such as analysis, synthesis, and evaluation when making decisions and solving problems (Claessen, 2004).

Experts in communication sciences and disorders (CSD), along with other health professions, have recognized the importance of preservice professionals' development of clinical reasoning skills, which is evidenced by recent additions to accreditation standards in the United States. Graduate speech-language pathology programs accredited by the Council on Academic Accreditation in Audiology and Speech-Language Pathology (CAA) are now required to provide students with learning opportunities that develop clinical reasoning skills. The standards require that preservice SLPs demonstrate the ability to:

Use valid scientific and clinical evidence in decision-making regarding assessment and intervention; apply current knowledge, theory, and sound professional judgment in approaches to intervention and management of individuals served; and use clinical judgment and self-reflection to enhance clinical reasoning. (CAA, 2019, p. 19)

Despite its significance in competent professional practice, few studies in CSD have investigated clinical reasoning. Hoben, Varley, and Cox (2007) noted preservice SLPs with diagnostic accuracy used more specific vocabulary and diagnostic statements, accessed and used theoretical knowledge more easily, and interpreted results and observations more accurately. Ginsberg, Friberg, and Visconti (2016) found preservice SLPs used similar clinical reasoning skills to those used by expert SLPs (e.g., hypothesizing, summarizing, rationalizing, seeking outside input, differentiating) during assessment planning; however, groups differed in how they compared cases, generated general and specific plans, and planned for treatment. In addition, experienced SLPs deferred (i.e. revealed a lack of knowledge or experience) because they had not worked recently with a type of client, whereas preservice SLPs' comments revealed more limited clinical experiences and knowledge overall (Ginsberg et al., 2016).

These studies offer preliminary investigations of the clinical reasoning skills SLPs use during diagnostic tasks, but an understanding of the clinical reasoning skills related to augmentative and alternative communication (AAC) service provision presents a notable gap in the literature. Although researchers have proposed decision trees, frameworks, and practice guidelines intended to inform SLPs' AAC clinical decisions, there are few studies about SLPs' actual decision making when supporting individuals who use AAC (Schlosser \& Raghavendra, 2004). General practice SLPs, clinical specialist SLPs, and research/policy specialists have reported using multiple procedures and considerations when planning for AAC assessments: case history, prep-time, language and communication assessments, symbol assessments, device trials, access methods, multi-modality approaches, instruction, and personalization (Dietz et al., 2012). When interviewed about their assessment approach for two children who might benefit from AAC, SLPs described 
informal, dynamic, and formal assessment procedures (Lund et al., 2017); however, underlying clinical reasoning skills were not reported in either study (Dietz et al., 2012; Lund et al., 2017).

In order to improve clinical education for preservice SLPs specifically for AAC service provision, it is important to identify the clinical reasoning skills expert SLPs use and to pinpoint where preservice SLPs might struggle in acquiring these skills. University faculty and clinical educators need to know the learning bottlenecks preservice SLPs experience in order to effectively redesign existing learning opportunities or design additional opportunities. "Decoding the Disciplines is a process for increasing student learning by narrowing the gap between expert and novice thinking" (Decoding the Disciplines, n.d., para. 1). The first two steps in the Decoding the Discipline process are to identify bottlenecks to learning and to uncover the mental tasks needed to overcome them (Decoding the Disciplines, n.d.). Expert performance on a clinical task can inform a working definition of competent clinical reasoning. Subsequent comparison of expert and novice performance can expose novices' strengths and weaknesses, thus revealing bottlenecks to student learning.

Despite preliminary findings on SLPs' clinical decision-making related to AAC service provision, the clinical reasoning skills that underlie those decisions have yet to be explored. Further, minimal research has focused on intervention planning as compared to assessment. Therefore, uncovering the mental tasks associated with clinical reasoning for AAC intervention planning was the primary purpose of this study. Labeling and defining clinical reasoning skills is important so that university faculty and clinical educators can support students in their development of these skills in the graduate classroom and clinical placements. With foundational knowledge of clinical reasoning skills, faculty and clinical educators can redesign or modify AAC coursework, clinical practica, and community-based experiences to cultivate effective clinical reasoning skills.

\section{Research Questions}

1. What clinical reasoning skills do expert and novice SLPs use when planning AAC intervention for children with developmental disabilities?

2. What were the differences and similarities between experts' and novices' clinical reasoning skills?

\section{Method}

Given the challenges of analyzing thoughts, think-alouds were used to make participants' clinical reasoning observable. During think-aloud tasks, inferencing and generative processes occur in real-time and the data represents participants' independent cognitive processes (Ericcson \& Simon, 1980; 1993; Ginsberg et al., 2016; Lund et al., 2017). Think-alouds were preferred over interviews or surveys, which may inadvertently guide participants' responses. Participants' responses were transcribed and qualitatively analyzed using methods consistent with grounded theory, and the findings were authenticated using quality indicators for data analysis in qualitative research, including peer debriefing and member checks (Brantlinger et al., 2005). This study had institutional review board approval and followed ethics procedures and standards governing research involving human subjects. 
Participants. Eight novices (i.e., preservice SLPs) and eight experts (i.e., AAC specialist SLPs) were recruited for participation through convenience sampling via direct email communication. Novices were recruited from the cohort of first-year graduate students at a Midwestern university. Expert participants were recruited through the researchers' professional networks.

Novices met the following inclusion criteria: (a) first-year speech-language pathology master student status (i.e., completed no more than two semesters of graduate study), (b) not yet begun an off-campus externship, and (c) completion of an introductory AAC course and/or clinical practicum with at least one client who uses AAC. Thus, all participants had completed either a course or practicum at the time of participation. Novice participants were between the ages of 21 and $34(M=25.13)$. The master's program from which novices were recruited allows students flexibility as to when they enroll in the introductory AAC course during their program. Further, not all novices had the opportunity to support a client who used AAC in their first semester of clinical practicum. As a result, novices' completion of an AAC course and/or clinical practicum varied. In addition, two novices had previously supported students who used AAC as paraprofessionals. Table 1 reports novices' demographic information and experience with AAC at the time of participation.

\section{Table 1}

Novice Participants' Demographic Information and Experience with AAC

\begin{tabular}{lccccccc}
\hline Novice & $\begin{array}{c}\text { Age in } \\
\text { Years }\end{array}$ & Gender & Race & $\begin{array}{c}\text { Completed } \\
\text { AAC course }\end{array}$ & $\begin{array}{c}\text { Completed } \\
\text { AAC } \\
\text { practicum }\end{array}$ & $\begin{array}{c}\text { Number of } \\
\text { AAC clients } \\
\text { supported in } \\
\text { practicum }\end{array}$ & $\begin{array}{c}\text { Experience } \\
\text { with children } \\
\text { who use AAC }\end{array}$ \\
\hline N1 & 23 & Female & White & Yes & Yes & 2 & No \\
N2 & 34 & Female & White & Yes & No & N/A & Yes \\
N3 & 23 & Female & $\begin{array}{c}\text { American } \\
\text { Indian }\end{array}$ & Yes & Yes & 2 & No \\
N4 & 22 & Female & White & No & Yes & 2 & No \\
N5 & 21 & Female & White & Yes & Yes & 1 & No \\
N6 & 33 & Female & White & Yes & No & N/A & No \\
N7 & 22 & Male & Black & Yes & Yes & 3 & No \\
N8 & 23 & Female & White & No & Yes & 3 & Yes \\
\hline
\end{tabular}

Expert inclusion criteria were informed by the AAC Assessment Personnel Framework (Binger et al., 2012), in which 50\% or more of AAC clinical specialists' (i.e., experts) daily work activities are related to AAC service provision. Thus, expert inclusion criteria were: (a) held a certificate of clinical competence in speech-language pathology for at least five years, (b) practiced as an SLP for at least five years, and (c) supported children who used AAC for at least $50 \%$ of daily work. Additional potential expert participants volunteered; however, those who completed the inclusion criteria survey and were the first to respond to requests for scheduling participated in the study. Experts' ages ranged from 37 to 64 years $(M=51.00)$. They had practiced between eight to 40 years $(M=22.00)$. Self-reported average percentage of daily work related to supporting children who use AAC ranged from $50 \%$ to $100 \%(M=81.88 \%)$. Table 2 presents experts' demographic information and practice experience. 
Table 2

Expert Participants' Demographic Information and Practice Experience

\begin{tabular}{lcllccccc}
\hline Expert & $\begin{array}{c}\text { Age } \\
\text { in } \\
\text { Years }\end{array}$ & Gender & Race & $\begin{array}{c}\text { Years SLP } \\
\text { practice } \\
\text { total }\end{array}$ & $\begin{array}{c}\text { Years AAC } \\
\text { experience }\end{array}$ & $\begin{array}{c}\text { Percentage of } \\
\text { workload } \\
\text { related to AAC }\end{array}$ & $\begin{array}{c}\text { Current work } \\
\text { environment }\end{array}$ & Region \\
\hline E1 & 62 & Female & White & 19 & 19 & 100 & School-based & Midwest \\
E2 & 64 & Female & White & 40 & 40 & 50 & School-based & Midwest \\
E3 & 59 & Female & White & 26 & 26 & 80 & School-based & Midwest \\
E4 & 37 & Female & White & 8 & 7 & 95 & School-based & Midwest \\
E5 & 49 & Female & White & 25 & 25 & 100 & Private practice & West \\
E6 & 42 & Female & White & 13 & 13 & 75 & Private practice & Midwest \\
E7 & 52 & Female & White & 27 & 12 & 90 & School-based & Midwest \\
E8 & 43 & Female & White & 18 & 18 & 65 & Private practice & Midwest \\
\hline
\end{tabular}

Data Collection. Participants engaged in two think-aloud tasks during an individual web conference meeting conducted via Zoom by the first author. Web conference meetings ranged from 45 to 75 minutes in duration, depending largely on the length of the participant's think-aloud responses. Think-aloud tasks addressed fictional case studies based loosely on Metzler-Barrack (2011) and Hart and Wiley (2011) but were modified by the first author to vary the duration of AAC device use, diagnosis, and impairment type. Christopher (Case Study C) is a child with a diagnosis of autism spectrum disorder, who had recently completed an AAC assessment and was just beginning to use a device (See Appendix A). Sam (Case Study S) is a child with cerebral palsy, who had been using a device for two years (See Appendix B). Thus, Christopher's impairment was primarily social in nature, whereas Sam's was motor-based. Half of the participants in each group were presented with Case Study C first and other half were presented with Case Study S first.

Webconference meetings included consent procedures, a warmup think-aloud task, and the two experimental think-aloud tasks. Participants read a case study to him or herself, then generated an intervention plan aloud. Specifically, the first author instructed participants to (a) plan for the first treatment session, (b) describe what the first session would look like, and (c) plan for future sessions. Participants developed their plan for a private practice setting in order to reduce contextspecific constraints of practicing in the schools. General prompts like "Tell me more" were used to elicit description or explanation as needed. After completing the first task, the participant read the second case study to themselves and completed the second think-aloud task. Audio and video recordings of webconference meetings were obtained for transcription and analysis. Note that these data were also analyzed related to intervention planning and are reported in the companion article (Sauerwein \& Wegner, 2020).

Data Analysis. The first author transcribed the verbal data verbatim. Each participant was assigned a number to protect participant identity. "Grounded theories, because they are drawn from data, are likely to offer insight, enhance understanding, and provide meaningful guide to action" (Strauss \& Corbin, 1998, p. 12). Consistent with grounded theory methods, analysis consisted of open, axial, and selective coding. Transcripts were analyzed using NVivo (Version 11), a qualitative data analysis software package.

Open coding began with the researcher coding each transcript line-by-line to identify and name emerging concepts that represented clinical reasoning skills. The researcher wrote a codebook that 
provided definitions and examples for each of the codes. Because the first author created the codebook independently, peer debriefing and member checks were used to authenticate the analyses (Brantlinger et al., 2005; Creswell \& Creswell, 2018). The first level of peer debriefing was provided by two experts (i.e., a qualitative researcher with think-aloud methods expertise and an AAC pedagogy expert), who reviewed the codebook and a subset of coded transcripts. They provided the researcher with feedback and made recommendations for analysis. Then, a graduate assistant provided peer debriefing by independently coding transcripts using the codebook. The first author and research assistant discussed and refined the codes and codebook until all transcripts had been discussed and 100\% intercoder agreement was reached on every code (Campbell et al., 2013).

Following peer debriefing, member checks provided participants an opportunity to (a) correct inaccuracies in their transcript and (b) provide feedback on analysis of their transcript (Guba \& Lincoln, 1989; Sandelowski, 2008). The first author contacted each participant to arrange a member check. All 16 participants provided written feedback on the analysis of their transcript via email. Their feedback, although minimal, was used to authenticate the codes and findings. In addition, research memos were used to keep an audit trail, or a record of data collection and analysis procedures (Brantlinger et al., 2005). Codes were consolidated into categories and themes, and informed a theoretical model, which is presented below.

\section{Results}

Six clinical reasoning skill subthemes emerged from the data, including summarizing, interpreting, hypothesizing, rationalizing, comparing, and deferring. All subthemes were present for both groups of participants, but differences were noted across groups. Table 3 presents the codebook definitions for each theme.

Table 3

Clinical Reasoning Subthemes

\begin{tabular}{|c|c|}
\hline Subtheme & Codebook Definition \\
\hline Summarizing & Providing a summary of information provided in the case study \\
\hline Interpreting & $\begin{array}{l}\text { Making assumptions or subjectively interpreting information in the case } \\
\text { study, particularly about the child's current level of functioning }\end{array}$ \\
\hline Hypothesizing & Making assumptions regarding prognosis or outcomes related to the case \\
\hline Rationalizing & Explaining why they would take a particular action \\
\hline Comparing & Making a comparison between the case and prior knowledge or experience \\
\hline Deferring & Commenting on a lack of knowledge or experience relative to the case study \\
\hline
\end{tabular}

Summarizing. Both groups of participants frequently summarized information included in the case study. Although there was individual variation and variation within groups in terms of frequency, the majority of participants summarized information ten times or more during the think- 
aloud tasks. Participants quoted information directly from the case study and/or repeated it in their own words. Information frequently summarized by both experts and novices included the cases' ages; language and literacy skills; motor skills; and characteristics about the device features, such as number of buttons per page. Participants also summarized details about family members and the children's education and other therapies.

Interpreting. Both experts and novices sometimes combined summarizing with interpreting. Interpretations included assumptions and inferences, particularly about the child's current level of functioning. All participants interpreted information at least four times, but most participants interpreted the case study 11 or more times. Both experts and novices interpreted case study details regarding cognition, attention to task, language skills, literacy skills, and use of the device. Most value-laden interpretations were positive in nature. Examples include, "He seems fairly proficient with [the device]" (N3) and "Sounds like he has got some great operational skills in terms of adjusting volume and on/off control" (E7). Interpretations also generally indicated potential for development and learning. An expert stated, "It sounds like he has so much potential" (E2) and a novice interpreted, "I would expect a 10-year-old with good cognition and receptive abilities um, ability to learn, to maybe possibly doing a little bit more" (N6). Participants' neutral or negative interpretations were typically stated professionally. For example, E3 said "If he has to navigate four displays to sequence two words, that's inefficient." Three participants differentiated, a form of interpreting that indicated differential or additional diagnoses. E3 thought Christopher might be delay-disordered and E4 noted he might be hyperlexic. The novice, who engaged in differentiating, wanted to be mindful of cortical visual impairment when working with Sam.

Hypothesizing. Overall, there were few instances of hypothesizing in the data. Six experts and six novices hypothesized by "making assumptions regarding prognosis or outcomes related to the case." Both groups of participants hypothesized that the children would make progress. Some made general statements like, "He's going to continue to do a great job" (N1) or "He might catch on pretty quick" (N8) about Sam. Regarding Christopher, E3 said, "I would think that with a four year old, and that development on my side, it might help" and N2 said, "It bodes fairly well for prognosis and for treatment that his receptive language skills do seem to be a little bit stronger than his expressive." Examples of more specific hypotheses include "[Christopher] looks like he's a kid that's gonna be an early reader" (E3) and "He should be able to handle a... high tech device" (N7).

Rationalizing. Rationalizing was the most frequently used clinical reasoning skill during the think-aloud tasks by both experts and novices. Participants rationalized their decisions as they developed intervention plans. Referencing evidence or research was also included in the rationalizing subtheme. A total of six experts and six novices referenced evidence when justifying their decisions, most of these participants did so only one or two times. Some participants mentioned researchers by name, but participants in both groups mentioned research more broadly. For example, a novice noted that video models have "been shown... in research to have success with... those with autism spectrum disorder" (N3). Overall, no major differences were observed in how experts and novices rationalized or referenced evidence or research in their intervention planning during the think-aloud task. 
Comparing. Although comparisons were relatively uncommon in the data set for both groups, comparing appeared more frequently in expert data than the novices' data. Novices' comparisons were limited to children of similar ages or to approaches used broadly in the university clinic. One novice said, "I know kids, especially 10 year olds, like to teach older people things, especially technology" (N5). Another novice planned to use a literacy program based on her experience doing so in the university clinic, "We do the ALL curriculum, and I've done that with a few clients and I've really enjoyed that" (N1). Not having supported a person with cerebral palsy herself, N4 compared Sam to a client a peer had supported in the university clinic. Conversely, experts compared the children in the cases by diagnosis, cerebral palsy or autism. For example, in reference to Christopher, an expert shared, "With kids with autism, when they come in to me... I like to have a set schedule. And I'll present...pictures and text along with... that schedule so he knows what activities we're going to be playing and when they're going to happen" (E3). Experts compared Christopher and Sam to "older kids" (Sam) or "younger kids" (Christopher). Experts were also more likely to mention specific therapy approaches they had used in the past with comparable clients.

Deferring. Experts and novices also differed in deferring (i.e., commenting on a lack of knowledge or experience relative to the case study). One expert and seven novices deferred during the thinkaloud tasks. An expert mentioned having difficulty switching therapy contexts by saying, "Sorry, I work in a school most of the time, so... I don't think private practice" and later went on to comment on her lack of recent experience with younger children, saying, "This is the other hard part. I don't work with little kids anymore" (E3). Although this participant had not worked with young children recently, she had useful prior experiences to draw on in this area.

On the other hand, novices' deferring was related to their more limited knowledge and clinical experience overall. For example, one novice commented on her lack of knowledge about cerebral palsy and an additional novice indicated having limited exposure to low-tech speech generating devices. Other novices described lack of knowledge about their instruction and collaboration with families. One novice wanted to incorporate literacy instruction with Sam, but said, "I'm not entirely sure about the sequence of teaching reading" (N7). Another novice planned to target letter-sound knowledge, but stated, "I don't have an activity off the top of my head" (N5). Referring to family education, a novice indicated, "I would certainly want to be making sure that as much as possible I'm training them in the process while I'm treating him um, so that he has that support around the clock and not just when he's at therapy. I'm not sure of the specifics of how I would do that" (N2).

\section{Discussion}

Experts and novices used four clinical reasoning skills similarly during the think-aloud tasks: summarizing, interpreting, hypothesizing, and rationalizing. The expert-novice gap in clinical reasoning, however, was evident in comparing and deferring. Novice SLPs' comparisons were limited and they deferred more frequently than experts. These differences reveal mental tasks that novice SLPs in the study could use additional support in developing during their graduate studies. Think-aloud data were further analyzed for participants' skills specific to intervention planning, such as planning activities and selecting targets. Intervention planning skills are presented in the companion article (Sauerwein \& Wegner, 2020). The results of this study have implications for teaching and learning related to AAC service provision. 
Implications for Teaching and Learning. How can a clinical educator evaluate a student's clinical reasoning skills if he or she does not know what to look for during a therapy session? How can a faculty member assess students' clinical reasoning in coursework if those skills are not observable within activities or assignments? Identifying and labeling specific clinical reasoning skills - and making often unobservable clinical reasoning skills, observable - are important steps in improving teaching and learning in this area. Given an understanding of bottlenecks and the mental tasks needed to overcome them, next steps to model those tasks, give novices opportunities to practice and provide feedback, and assess novice learning (Decoding the Disciplines, n.d.). AAC course and clinical practica instructors might support novice learning related to comparing and deferring, the two clinical reasoning skills that were challenging for novices in this study. However, it is important to note that the expert-novice gap described in this study refers to the eight expert and eight novice participants only. It is certainly reasonable to expect individual differences among novice SLPs' development of clinical reasoning skills. Thus, it remains important to evaluate novices' abilities to summarize, interpret, hypothesize, and rationalize - and to be aware of other clinical reasoning skills that may emerge - as they approach clinical cases.

Building prototype databases for comparisons. Experts in the study drew on their experiences and prototypes of children with autism and cerebral palsy and providing services in private practice, whereas novices' comparisons relied on their limited experiences treating in the university clinic and their broad knowledge about supporting children with complex communication needs. Ginsberg and colleagues (2016) suggest that novice SLPs should be exposed to a variety of clinical cases and problems in order to develop a prototype database, which experts use to guide their clinical decision-making. As novices gain experience, they can add exemplars to their prototype database, which extends their textbook knowledge of communication disorders. Acquiring a robust prototype database can be addressed in the classroom and the clinic (Ginsberg et al., 2016). Strategically incorporating problem- and team-based learning can increase novices' exposure to a variety of clinical populations, including people who use AAC systems.

Problem-based learning is a student-centered approach to teaching that provides students opportunities to analyze clinical cases (Ginsberg et al., 2012; Whitehill et al., 2014). Instructors assign students an authentic clinical problem, serve as a collaborator, and provide feedback on learning. Feedback addresses what novices learn, but also how they learned it, which is particularly relevant to clinical reasoning skill development (Ginsberg et al., 2012). Instructors can certainly use problem-based learning when teaching AAC coursework by incorporating problems and cases related to supporting individuals who use AAC systems (Greenwald, 2006; Raghavendra, 2009). However, fully integrating problem-based learning across the speech-language pathology curriculum has the potential to yield even richer prototype databases as novices gain exposure to a wide variety of clinical cases across their coursework (Burda \& Hageman, 2015; Visconti, 2010; Whitehill et al., 2014). Think-aloud tasks can be used as formative or summative assessment tools and provide opportunities for instructors to observe novices' clinical reasoning skills in action. In the clinic, team-based learning can be used in lieu of traditional one-on-one teaching and learning to help novices more swiftly build prototype databases. Team-based clinical education can vary widely in format, but the primary component is case-based collaborative problem-solving with peers and clinical educators (Dudding et al., 2017). Regular exposure to other novices' cases, and the ability to compare these cases to their own clients, is likely to foster more robust prototype development earlier in their preservice education. 
Increasing capacity and access to resources. In addition to enhancing novices' prototype databases, it is important that they build capacity in AAC service provision to address deferring, which reflects a lack of knowledge or experience. An upward trend in the availability of AAC coursework and clinical practica has been noted in the United States in recent decades, but there continues to be gaps in AAC preservice education (Johnson \& Prebor, 2019; McNaughton et al., 2018). There is a need for increased representation of individuals who use AAC in university clinics and clinical externship placements so that more novices can graduate with clock hours in AAC (Johnson \& Prebor, 2019). Nonetheless, courses and clinical experiences that are already available to novices should meaningfully address the knowledge, skills, and resources novices need to be successful in supporting people who use AAC.

McNaughton and colleagues (2018) propose that coursework and clinical experiences should facilitate a shift in novice SLPs' solutions, from novice to more expert solutions. Novice solutions are habitual or based on the SLP's familiarity with an intervention approach, whereas expert solutions are unique to the person who uses AAC (McNaughton et al., 2018; Schlosser \& Raghavendra, 2004). Providing individualized services requires extensive knowledge and skills. This study and others (Dietz et al., 2012; Lund et al., 2017) have uncovered skills that can be addressed in courses and clinical experiences. Best practice frameworks can be useful for reference as well (Schlosser \& Raghavendra, 2004). For example, related to assessment, novices can learn how to prepare for AAC evaluations, use dynamic assessment methods, conduct device trials, assess access methods, and adopt multi-modality approaches when personalizing AAC systems (Dietz et al., 2012; Lund et al., 2017). The companion article (Sauerwein \& Wegner, 2020) presents skills that novices can develop related to AAC intervention planning. Finally, only so much can be learned in any one course or clinical placement. SLPs are ultimately responsible for continuing their education and locating the resources they need to be successful in practice. Instructors should ensure these novice SLPs know how and where to access resources and high quality professional development opportunities related to AAC.

Conclusion. In conclusion, this study revealed six clinical reasoning skills expert and novice SLPs used when planning for AAC intervention with children with developmental disabilities summarizing, interpreting, hypothesizing, rationalizing, comparing, and deferring. The expertnovice gap highlighted the need for improving teaching and learning by addressing bottlenecks, which were in the areas of comparing and deferring for the novices in this study. Problem- and team-based learning offer opportunities to develop novice SLPs' prototype databases. Courses and clinical experiences should strategically increase novices' knowledge, skills, and access to resources so they can become proficient in supporting individuals who use AAC in practice.

Limitations and Future Directions. Limitations of the study are related to sampling, peer debriefing in data analysis, and the authenticity and generalization of think-aloud data. First, eight experts and eight novices participated in the study, resulting in a small sample size. Novices were recruited from one university and experts were convenience sampled through personal networks. As a result, participants were not racially nor ethnically diverse and all lived in the Midwestern United States. Overall, the results represent these participants' clinical reasoning skills, but might not be representative of other SLPs' or students' skills. Further, novice participants had taken an AAC course and/or completed a clinical practicum at the time of participation (i.e., some participants had completed both, whereas others had completed only an AAC course or only a 
clinical practicum). This lack of consistent exposure to AAC content is an additional limitation. Second, a graduate research assistant was the primary peer debriefer. This assistant was not an expert in qualitative data analysis, nor was she familiar with think-aloud methods. This limitation was addressed by having a qualitative data analysis expert and an AAC pedagogy expert serve as secondary and tertiary peer debriefers. Lastly, think-aloud data revealed how participants plan for intervention, but may not reflect actual implementation. The researcher did not observe participants implement an intervention plan nor analyze their written intervention plans, which could increase the ecological validity of the results. In addition, participants were instructed to develop their plan for therapy in private practice setting. Although this was intended to provide participants with greater flexibility in their therapy planning, the results of this study may not reflect how participants would plan for therapy in the schools or other clinical environments.

Future research should address these limitations by including participants with diverse experiences and from different preservice programs. Because children who use AAC have a variety of diagnoses and communication needs, and SLPs support them in multiple work environments, it is important that cases used in future research reflect these nuances. It is also important to examine how planning for intervention translates into actual practice. Triangulating methods would be useful in this endeavor, perhaps by assessing clinicians' performance in therapy sessions. Finally, although the purpose of this study was to investigate the expert-novice gap, differences in clinical reasoning skills were observed within participant groups as well. This is not surprising, as professionals and students alike have differing strengths and weaknesses. Additional research should further examine the range of novice performance as their development of clinical reasoning skills has implications for clinical practice. Pinpointing individual novices' strengths and weaknesses is essential to modifying learning opportunities to meet each student's unique learning needs.

\section{Disclosures}

The authors have no relevant financial or nonfinancial relationships to disclose.

\section{References}

Binger, C., Ball, L., Dietz, A., Kent-Walsh, J., Lasker, J., Lund, S., . . . Quach, W. (2012). Personnel roles in the AAC process. Augmentative and Alternative Communication, 28, 278-288. https://doi.org/10.3109/07434618.2012.716079

Brantlinger, E., Jimenez, R., Klinger, J., Pugach, M., \& Richardson, V. (2005). Qualitative studies in special education. Exceptional Children, 71, 195-207. https://doi.org/10.1177/001440290507100205

Burda, A. N., \& Hageman, C. F. (2015). Problem-based learning in speech-language pathology: Format and feedback. Contemporary Issues in Communication Science and Disorders, 42, 47-71. https://doi.org/10.1044/cicsd_42_S 47

Campbell, J. L., Quincy, C., Osserman, J., \& Pedersen, O. K. (2013). Coding in-depth semistructured interviews: Problems of unitization and intercoder reliability. Sociological Methods \& Research, 42, 294-310. https://doi.org/10.1177/0049124113500475 
Claessen, J. (2004). A 2:1 clinical practicum, incorporating reciprocal peer coaching, clinical reasoning, and self-and-peer-evaluation. Journal of Speech-Language Pathology and Audiology, 28(4), 156-165.

Council on Academic Accreditation in Audiology and Speech-Language Pathology. (2019). Summary of revisions to standards for accreditation of graduate education programs in audiology and speech-language pathology. https://caa.asha.org/wpcontent/uploads/Accreditation-Standards-for-Graduate-Programs.pdf

Creswell, J. W., \& Creswell, J. D. (2018). Research design: Qualitative, quantitative, and mixed methods approaches. SAGE Publications.

Decoding the Disciplines. (n.d.). Decoding the Disciplines: Improving Student Learning. http://www.decodingthedisciplines.org

Dietz, A., Quach, W., Lund, S. K., \& McKelvey, M. (2012). AAC assessment and clinicaldecision making: The impact of experience. Augmentative and Alternative Communication, 28, 148-159. https://doi.org/10.3109/07434618.2012.704521

Dudding, C. C., McCready, V., Nunez, L. M., \& Procaccini, S. J. (2017). Clinical supervision in speech-language pathology and audiology in the United States: Development of a professional specialty. The Clinical Supervisor, 36(2), 161-181. https://doi.org/10.1080/07325223.2017.1377663

Ericcson, K. A., \& Simon, H. A. (1980). Verbal reports as data. Psychological Review, 87, 215-251.

Ericcson, K. A., \& Simon, H. A. (1993). Protocol analysis: Verbal reports as data. Cambridge, MA: MIT Press.

Ginsberg, S. M., Friberg, J. C., \& Visconti, C. F. (2012). Scholarship of teaching and learning in speech-language pathology and audiology: Evidence-based education. Plural Publishing.

Ginsberg, S. M., Friberg, J. C., \& Visconti, C. F. (2016). Diagnostic reasoning by experienced speech-language pathologists and student clinicians. Contemporary Issues in Communication Science and Disorders, 43, 87-97. https://doi.org/10.1044/cicsd_43_S_87

Greenwald, M. L. (2006). Teaching research methods in communication disorders: A problembased learning approach. Communication Disorders Quarterly, 27(3), 173-179. https://doi.org/10.1177/15257401060270030501

Guba, E. G., \& Lincoln, Y. S. (1989). Fourth generation evaluation. SAGE Publications.

Hart, P., \& Wiley, S. (2011). Sam: Assessment and intervention for a school-age child with complex communication needs and physical impairments. In S. Chabon, \& E. Cohn (Eds.), The communication disorders casebook: Learning by example (pp. 206-214). Pearson Education.

Hoben, K., Varley, R., \& Cox, R. (2007). Clinical reasoning skills of speech and language therapy students. International Journal of Language and Communication Disorders, 42(S1) 123-135.

Johnson, R. K., \& Prebor, J. (2019). Update on preservice training in augmentative and alternative communication for speech-language pathologists. American Journal of SpeechLanguage Pathology, 28(2), 536-549. https://doi.org/10.1044/2018_AJSLP-18-0004

Lund, S., Quach, W., Weissling, K. S. E., McKelvey, M. L., \& Dietz, A. R. (2017). Assessment with children who need augmentative and alternative communication (AAC): Clinical decisions of AAC specialists. Language, Speech, and Hearing Services in Schools, 48, 56-68. https://doi.org/10.1044/2016_LSHSS-15-0086 
McAllister, L., \& Rose, M. (2008). Speech-language pathology students: Learning clinical reasoning. In Higgs, J., Jones, M., Loftus, S., \& Christensen, N. (Eds.), Clinical Reasoning in the Health Professions (pp. 397-404). Elsevier.

McNaughton, D., Light, J., Beukelman, D. R., Klein, C., Nieder, D., \& Nazareth, G. (2018). Building capacity in AAC: A person-centered approach to supporting participation by people with complex communication needs. Augmentative and Alternative Communication, 35(1), 56-68. https://doi.org/10.1080/07434618.2018.1556731

Metzler-Barrack, B. (2011). Christopher: Speech and language intervention for a child with autism: A relationship-based approach. In S. Chabon, \& E. Cohn (Eds.), The communication disorders casebook: Learning by example (pp. 88-94). Pearson Education.

Raghavendra, R. (2009). Teaching evidence-based practice in a problem-based learning course in speech-language pathology. Evidence-based Communication Assessment and Intervention, 3, 232-237. https://doi.org/10.1080/17489530903399160

Sandelowski, M. (2008). Member check. In L. Given (Ed.), The SAGE encyclopedia of qualitative research methods (pp. 501-502). SAGE Publications.

Sauerwein, A. M., \& Wegner, J. R. (2020). Using think-alouds to uncover expert-novice gaps in AAC intervention planning. Teaching and Learning in Communication Sciences \& Disorders. http://tlcsdjournal.com

Schlosser, R. W., \& Raghavendra, P. (2004). Evidence-based practice in augmentative and alternative communication. Augmentative and Alternative Communication, 20(1), 1-21. https://doi.org/10.1080/07434610310001621083

Strauss, A., \& Corbin, J. (1998). Basics of qualitative research: Techniques and procedures for developing grounded theory (2nd ed.). SAGE Publications.

Visconti, C. F. (2010). Problem-based learning: Teaching skills for evidence-based practice. Perspectives on Issues in Higher Education, 13(1), 27-31. https://doi.org/10.1044/ihe13.1.27

Whitehill, T. L., Bridges, S., \& Chan, K. (2014). Problem-based learning (PBL) and speechlanguage pathology: A tutorial. Clinical Linguistics and Phonetics, 28(1-2), 5-23. https://doi.org/10.3109/02699206.2013.821524 


\section{Appendix A}

\section{Case Study C}

Christopher is a 4 year, 0 month old male who has a diagnosis of Autism Spectrum Disorder (ASD). Christopher's vision and hearing were recently screened and judged to be within normal limits. He achieved some developmental milestones within normal limits; for example, he rolled over at 4 months, crawled at 9 months, and walked at 13 months; however, he said his first word at 18 months and his expressive vocabulary is limited Christopher indicates his wants and needs by using contact gestures and speech approximations. Christopher lives at home with his mother, father, and two older sisters.

During a recent evaluation, the speech-language pathologist noted that Christopher typically uses jargon with a few real words. Based on standardized assessment, his receptive language skills are at the 18-21-month level and his expressive language skills are at the 15-18-month level. He has some skills that are above age expectations, including identifying (by pointing) all letters of the alphabet and some shapes and colors. Overall, Christopher presents with marked impairments in his nonverbal behaviors, ability to form peer relationships, and lack of social and emotional reciprocity. He also has a delay of spoken language and lack of varied make-believe and symbolic play. Christopher attends an early childhood center and participates in speech/language therapy and occupational therapy at school.

As a result of an AAC evaluation, it was recommended that Christopher obtain a low-tech static speech-generating device with 32 buttons per page. He received the device yesterday. He has demonstrated initial interest in the device and has explored the device by selecting each of the buttons and attending and listening to the speech output. Christopher is ambulatory and is able to carry the device independently. He uses his right index finger to access the device independently. 


\section{Appendix B}

\section{Case Study S}

Sam is a 10-year old male who was born with a form of spastic cerebral palsy, and as a result, is unable to walk or speak intelligibly and has severely limited use of his hands. Sam lives at home with his mother, father, and younger sister. He uses a manual wheelchair, and he requires assistance for mobility. Sam's vision is satisfactory, with a recent examination indicating 20/20 acuity, and his hearing abilities are within normal limits.

Prior to an AAC assessment at age 8, Sam communicated by responding to yes/no questions by turning his head to the right to indicate "yes" or to the left to indicate "no." He used this strategy to meet his basic wants and needs and to participate in the modified curriculum he participated in a self-contained room at school. The speech-language pathologist who conducted the AAC assessment recommended a high-tech speech-generating device with dynamic display with eye gaze access. Sam has now used the recommended device for the two years since the assessment. The device is mounted to his wheelchair.

Currently, Sam spends half of his school day in the general education classroom. In the last two years, he has learned to: 1) navigate to 12 pages within the device consistently, 2) adjust volume and on/off controls, 3) initiate basic greetings and farewells with peers and caregivers, and 4) extend turn-taking during a conversation with caregivers and peers to 2 comments on the same topic. However, he uses approximately only $25 \%$ of the core vocabulary on the device's main page, which has 48 buttons. The majority of his utterances are 1-2 words in length. Sam's parents, teachers, and therapists report that he is very social and eager to communicate.

Although Sam's cognition has not been formally evaluated, he exhibits good ability for new learning and good attention to task. His receptive language skills are a relative strength, as Sam demonstrates understanding of conversation, multi-step directions, and humor. He is currently in the early stages of literacy development. Using eye gaze with letters placed in the four quadrants of the device screen, Sam demonstrates letter-sound knowledge for 13/26 lowercase letters. 